\title{
Understanding heterogeneity among elderly consumers: an evaluation of segmentation approaches in the functional food market
}

\author{
Lotte D. T. van der Zanden ${ }^{1 *}$, Ellen van Kleef $^{1}$, René A. de Wijk ${ }^{2}$ and Hans C. M. van Trijp ${ }^{1}$ \\ ${ }^{1}$ Marketing and Consumer Behaviour Group, Department of Social Sciences, Wageningen University, Hollandseweg 1, \\ $6706 \mathrm{KN}$ Wageningen, The Netherlands \\ ${ }^{2}$ Food and Biobased Research, Consumer Science and Intelligent Systems, Wageningen University, PO Box 17, \\ 6700 AA Wageningen, The Netherlands
}

\section{Abstract}

It is beneficial for both the public health community and the food industry to meet nutritional needs of elderly consumers through product formats that they want. The heterogeneity of the elderly market poses a challenge, however, and calls for market segmentation. Although many researchers have proposed ways to segment the elderly consumer population, the elderly food market has received surprisingly little attention in this respect. Therefore, the present paper reviewed eight potential segmentation bases on their appropriateness in the context of functional foods aimed at the elderly: cognitive age, life course, time perspective, demographics, general food beliefs, food choice motives, product attributes and benefits sought, and past purchase. Each of the segmentation bases had strengths as well as weaknesses regarding seven evaluation criteria. Given that both product design and communication are useful tools to increase the appeal of functional foods, we argue that elderly consumers in this market may best be segmented using a preference-based segmentation base that is predictive of behaviour (for example, attributes and benefits sought), combined with a characteristics-based segmentation base that describes consumer characteristics (for example, demographics). In the end, the effectiveness of (combinations of) segmentation bases for elderly consumers in the functional food market remains an empirical matter. We hope that the present review stimulates further empirical research that substantiates the ideas presented in this paper.

Key words: Segmentation approaches: Elderly: Mature consumers: Functional foods

\section{Introduction}

The elderly population is becoming an increasingly interesting consumer group from a marketing perspective. The proportion of elderly aged 65 years and older in the population is expected to rise to $20 \%$ for the USA ${ }^{(1)}$ and to $29 \%$ for Europe ${ }^{(2)}$ in the next 40 years. In addition, elderly consumers are getting wealthier ${ }^{(3)}$. Therefore, marketers are starting to focus their efforts on the unique needs of the elderly, in particular in the tourism domain $^{(4,5)}$. For many other domains, including the food domain, the elderly market is still under development ${ }^{(6,7)}$.

The food market holds great potential for targeting the elderly population. The nutritional needs of elderly change with advancing age, as do their preferences regarding how to meet these needs. Specifically, appetite declines with age whereas the recommended daily intake of many nutrients increases ${ }^{(8)}$. This paradox can result in nutritional deficiencies, which decrease the quality of life of elderly ${ }^{(9)}$ and increase healthcare costs ${ }^{(10)}$. Moreover, elderly show an interest in healthy eating ${ }^{(11)}$ and are willing to spend money on products that meet their needs ${ }^{(12,13)}$. Marketing efforts that focus on the nutritional needs of elderly may thus be beneficial for both public health and the food industry.

However, from a marketing perspective, meeting these needs is challenging. First, elderly who face a reduced appetite will probably not be able to meet their nutritional needs through an increased quantity of consumption. A more promising approach may therefore be the commercialisation of nutrient-enriched food ${ }^{(14)}$, which is a type of functional food $^{(15)}$ that is relatively nutrient-dense given its volume. Commercialising these foods may pose a second challenge. Functional foods that are specifically aimed at elderly consumers may not be readily accepted by all subgroups of the elderly population, due to age-related stigmatisation $^{(16,17)}$. In contrast, when functional foods are advertised as healthy alternatives to conventional products, elderly are overall willing to try them ${ }^{(18-20)}$. The general concept of functional food may thus appeal to elderly. Nonetheless, specific functional food products 
may not, which is a third challenge to meeting the nutritional needs of the elderly. Although the elderly population can be classified using an age bracket (defined here as age 55 years and older), it is strongly heterogeneous in its composition $^{(6)}$. During the decade from age 50 to 60 years, consumers go through many life changes and therefore become less alike ${ }^{(21)}$. Consequently, elderly may have similar nutritional needs (i.e. nutrient requirements), but their food-related wants (i.e. product preferences) tend to differ strongly.

Heterogeneous populations like the elderly call for a strategic marketing approach based on segmentation, targeting and positioning. Segmentation entails the identification of smaller, more homogeneous subgroups (segments) within a broader, more heterogeneous population ${ }^{(22)}$. Once identified, segments can be evaluated on their potential for a specific company, and one or more segments can be selected for targeting. For these target segments, differentiated marketing programmes can be developed based on product design and positioning. Many researchers have recognised the heterogeneity among elderly and have proposed ways to segment this population ${ }^{(4,17,21)}$. Nonetheless, segmentation within the elderly food market has received surprisingly little attention, especially when compared with the travel market. To our knowledge, only two published articles have focused on segmenting elderly consumers in the food market ${ }^{(23,24)}$ and none has focused on the functional food market.

A successful approach will promote the commercialisation of functional foods for the elderly. However, successful segmentation is not simply a matter of freely exploring consumer differences, because segments are not groups of consumers that occur naturally in the market ${ }^{(22)}$. Instead, segments are groups created by marketers to help them develop market strategies and meaningful groups result only from a strong theoretical basis. Therefore, one of the most critical steps in market segmentation is the selection of one or multiple variables (bases) that will be used to group consumers into segments ${ }^{(22)}$. Although, statistically, segments can be found even when a logical basis for clusters is not apparent ${ }^{(25)}$, an inappropriate choice of base variables may result in segments that are hard to identify or do not provide informative input for marketing efforts. In contrast, a (combination of) well-selected base(s) may provide marketers with more valid segments that differ from each other in a meaningful way. Therefore, the aim of the present paper is to review a range of potential segmentation bases, and critically evaluate their appropriateness in the context of functional foods aimed at the elderly.

\section{Segmentation bases}

Food choice depends on various interrelated higher-level and lower-level determinants, and each of these sources of variability might potentially serve as a segmentation base ${ }^{(21,26)}$. To provide some structure in discussing these various bases, we organise them into three hierarchical levels that (amongst others) are regularly used in consumer research: the person, domain and product level ${ }^{(27-29)}$. Bases on the person level (also called 'general level') exist on an abstract, high level and consist of global consumer differences such as demographics (for example, marital status) and general psychographics (for example, personality). Bases on the domain or (in this case) food level exist on a medial level and consist of food-specific consumer differences, such as general beliefs and motives regarding food. Bases on the product level exist on a concrete, low level and are represented by product-specific consumer differences, such as the benefits and attributes sought by consumers as well as their product purchase behaviour.

We evaluate and compare a range of these higher- and lower-level segmentation bases, to determine the extent to which they can provide useful information for marketing efforts within the elderly functional food market. Based on an extensive survey of the literature and discussion among the authors, we narrow our review to: four person-related bases (cognitive age, life course, time perspective and demographics), two food-related bases (general food beliefs and food choice motives) and two product-related bases (product attributes and benefits sought, and past purchase) (see Fig. 1). These segmentation bases are frequently discussed in either literature on the elderly population, food choice or both, and have all been studied in the context of consumer behaviour.

Among these eight bases on three levels, one can distinguish between two main sets of segmentation approaches: characteristics-based $v$. preference/needs/ benefit-based segmentation (from now on referred to as 'preference-based'). Characteristics-based segmentation mainly organises consumers into groups with similar personal characteristics and provides input for segment communication and targeting. In contrast, preferencebased segmentation organises consumers into groups

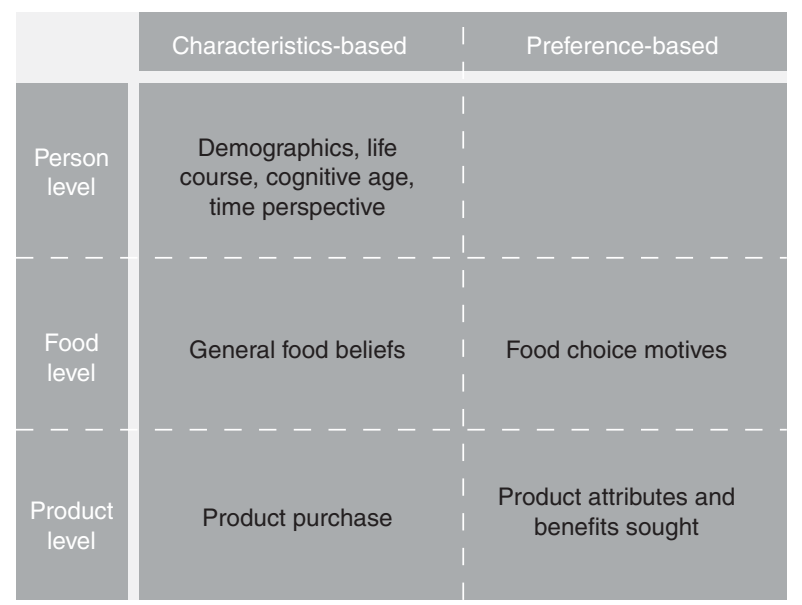

Fig. 1. Theoretical organisation of the selected eight potential segmentation bases. 
with similar needs and wants and provides input for product development and strategy ${ }^{(30-32)}$. In markets like the functional food market, both product development and communication for (re)positioning of existing products are useful; thus, either of the two main segmentation approaches may be suitable for segmenting elderly in the functional food market. We will use this theoretical organisation as a starting point for evaluating the eight selected segmentation bases on a set of evaluation criteria.

\section{Evaluation criteria}

The marketing literature has put forward six criteria for the evaluation of market segmentation approaches: identifiability, substantiality, accessibility, stability, responsiveness and actionability ${ }^{(22,33,34)}$. These criteria are operationalised as follows:

(1) Identifiability: segments can be distinguished from each other on the basis of information that is obtained objectively and easily (for example, a validated and short scale).

(2) Substantiality: segments are large enough to be targeted profitably in terms of invested time, effort and cost as well as resulting sales.

(3) Accessibility: targeted segments can be reached with marketing efforts through multimedia or in store in a way that is not too costly. Media profiles (based on demographics) provide information on how marketers can access segments.

(4) Stability: segments are stable for at least the time that marketing efforts take place in terms of size, behaviour or consumer membership.

(5) Responsiveness: consumers within segments respond similarly to marketing efforts targeted at them and uniquely different from consumers in other segments.

(6) Actionability: segments are meaningful in that they provide instructions for the development of marketing efforts within the scope of a company's capabilities.

The relative importance of these six criteria depends, to some degree, on the marketing objectives of the segmentation. As mentioned before, product development and communication are important tools to increase the appeal of functional foods. Given that their success depends largely on the actionability of a segmentation base, we split the criteria of actionability into actionable for design and actionable for communication. This leaves us with seven evaluation criteria. Ideally, a segmentation base is strong regarding all criteria. However, most bases face some weaknesses as well as strengths ${ }^{(22,35)}$, and it may be most useful to segment consumer populations on a combination of variables that complement each other $^{(22)}$. We will evaluate the strengths and weaknesses of the individual eight bases first (summarised in Table 1) and elaborate on complementary combinations of variables in the Discussion section.

\section{Person-level bases}

Person-level segmentation bases are high-level bases that indicate, for example, how people perceive their future (for example, 'full of opportunities') and themselves (for example, 'younger than my chronological age'), but also their place in society (for example, 'unemployed' or 'married'). Researchers who advocate the use of person-level bases for market segmenting generally argue that these provide a broad perspective on consumer behaviour and that segments are generalisable to various domains ${ }^{(21,36)}$ Others argue that these segments may be too broad and therefore not able to explain and predict specific behaviour $^{(24,27)}$. We will evaluate four person-level bases: cognitive age, life course, time perspective and demographics.

\section{Cognitive age}

In the past, age was frequently used as a segmentation base ${ }^{(37,38)}$. However, since the $1990 \mathrm{~s}$, marketers have started to acknowledge that people do not 'act their age' and that people within the same age group are rather dissimilar $^{(6)}$. Chronological age is an empty variable, in the sense that it does not cause behaviour ${ }^{(39)}$, but merely gives a suggestion of one's degree of ageing. Age, in turn,

Table 1. Strengths and weaknesses of potential segmentation bases by evaluation criteria

\begin{tabular}{llllllll}
\hline & ID & SUB & ACC & STA & RES & aCOM & aDSG \\
\hline $\begin{array}{lllllll}\text { Person-level bases } \\
\quad \text { Cognitive age }\end{array}$ & +- & +- & +- & ++ & ++ & +- & -- \\
$\quad$ Life course & -- & ++ & +- & ++ & ++ & -- & -- \\
$\quad \begin{array}{l}\text { Time perspective } \\
\text { Demographics }\end{array}$ & +- & -- & -- & +- & ++ & ++ & ++ \\
$\begin{array}{l}\text { Domain-level bases } \\
\quad \text { General food beliefs }\end{array}$ & ++ & ++ & ++ & ++ & -- & -- & -- \\
$\quad \begin{array}{l}\text { Food choice motives } \\
\text { Product-level bases }\end{array}$ & +- & ++ & -- & +- & ++ & +- & +- \\
$\quad \begin{array}{l}\text { Attributes and benefits } \\
\text { Past purchase }\end{array}$ & -- & ++ & -- & +- & ++ & ++ & ++ \\
\hline
\end{tabular}

ID, identifiability; SUB, substantiality; ACC, accessibility; STA, stability; RES, responsiveness; aCOM, actionability for communication; aDSG, actionability for design. 
is not perfectly in line with ageing ${ }^{(36)}$. Ageing occurs at different rates in different people and elderly often feel much younger than their chronological age ${ }^{(40)}$. As a result, chronological age has made way for cognitive age; the age one feels like, looks like, acts like and the age one's interests fit in ${ }^{(38,41)}$.

Cognitive age results from biological, psychological and social ageing, which affect how people perceive themselves $^{(40)}$. After retirement, for example, people may start feeling old because they want to maintain consistency between their behaviour and their identity ${ }^{(40)}$. Nonetheless, the majority of elderly do not feel old ${ }^{(42)}$, which may be partly explained by the perceived undesirability of old age that exists in many societies ${ }^{(16,42)}$. Also, the turning point from feeling young to feeling old may require the experience of a catalytic event, rather than ageing in general $^{(43)}$, and the timing of this event probably differs considerably among individuals because people respond differently to life events ${ }^{(9,40,44)}$. However, as long as one lives in a stable environment, cognitive age may remain constant or change slowly ${ }^{(40)}$. In line with this, the testretest reliability of the cognitive age scale is strong; $0 \cdot 88^{(38,41)}$

Cognitive age mediates the effect of various demographics on behaviour ${ }^{(40)}$ and it may therefore provide a rich perspective of consumers, resulting in uniquely responsive segments. Cognitively old elderly, for example, are more price sensitive than cognitively young elderly ${ }^{(45)}$ Given the overall higher prices of functional food ${ }^{(46)}$, cognitively old elderly may thus be less interested in purchasing these types of food than cognitively young elderly. However, to our knowledge, there is no literature available on the relationship between cognitive age and (functional) food choice.

Cognitive age is a better predictor of behaviour than chronological age ${ }^{(43)}$. Nevertheless, as a person-level variable, cognitive age is limited in predicting food choice. In addition, segments based on cognitive age are not as easily identified as segments based on chronological age. Whereas chronological age can be determined objectively and directly, using a single question, cognitive age is inferred from responses on a multi-item questionnaire, albeit a small and reliable one (split-half reliability: $0 \cdot 85)^{(41)}$. Moreover, there is no consensus on how to categorise subjects into cognitive age groups. One could, for example, use a cut-off score to categorise people into cognitively young $v$. old, or one could distinguish between people who feel younger or older than their actual age. Although this lack of consensus reduces identifiability of segments based on cognitive age, it does provide marketers with some influence on the composition and substantiality of segments; there is no fixed number of segments (in contrast with, for example, sex).

Irrespective of the operationalisation of its groups, cognitive age provides limited instructions for marketing efforts. Questions may be raised such as: do elderly who feel like 60 want different functional foods from those who feel like 90? Actionability for product design is thus limited and, therefore, researchers usually recommend combining cognitive age with other variables ${ }^{(36,43)}$. Segments do provide some instructions for communication efforts and are moderately actionable for communication. For example, research on age-related stigmatisation has shown that cognitively old elderly accept age-targeted products and services such as senior discounts, whilst cognitively young elderly do not ${ }^{(16,47)}$. Furthermore, media profiles based on chronological age may provide some information on how marketers can access segments based on cognitive age, since they are correlated $(r>0.50)^{(40,42)}$. Media profiles based on other demographics may not be applicable because they are only weakly related to cognitive age ${ }^{(40,43)}$.

\section{Life course}

Whereas cognitive age perspectives assume that life events affect one's self-perception, life course perspectives argue that elderly who experienced similar life events will have similar needs, wants and/or behaviours ${ }^{(6,21)}$. Life events like retirement, remarriage, becoming a grandparent, relocation, health problems and widowhood ${ }^{(48)}$ have all been studied in the context of food consumption, but their effects tend to vary from one person and situation to another $^{(44,49)}$. Retirement, for example, may provide people with more time to prepare and enjoy meals, but may also increase the tendency to snack out of boredom or inactivity ${ }^{(44)}$. This variability can be explained by the idea that life events have various direct and indirect effects $^{(49)}$ that interact with each other in a dynamic way ${ }^{(44)}$.

Because life events cannot be viewed in isolation ${ }^{(49)}$, most researchers use combinations of life events. One example is the gerontographic life-stage model, which is specifically aimed at segmenting the elderly population. The model proposes four substantial segments: healthy indulgers (13\%), healthy hermits (38\%), ailing outgoers $(34 \%)$ and frail recluses $(15 \%)^{(21)}$, which consist of elderly who are at different but not necessarily sequential stages in their lives ${ }^{(37)}$. In part because segments are based on a wide collection of measures, the life-stage model predicts behaviour better than chronological age, cognitive age $^{(21,50)}$ or demographics ${ }^{(51)}$ alone and segments are differentially responsive. Ailing outgoers, for example, are interested in learning new things, whilst frail recluses want to feel secure ${ }^{(50)}$. However, the extent to which different marketing strategies appeal to the segments varies across products $^{(21)}$ and segments are, therefore, limited in actionability regarding both product design and communication. In addition, it has been suggested that only two segments are viable for the food market: healthy indulgers and ailing outgoers ${ }^{(52)}$.

In contrast, stability of segments based on life course perspectives is probably good, because life events are 
closely linked with demographics (for example, retirement with income and occupation), which are generally stable. In line with this, the gerontographic life stages are relatively stable, with segments varying in size by no more than $2 \%$ across studies ${ }^{(21)}$. Moreover, some of the demographic information inherent in life events can be linked to media profiles (for example, socio-economic status), which provides marketers with information on the accessibility of segments. Although single life events may be easily identifiable using objective and direct demographic questions, questionnaires that assess a collection of life events can become quite lengthy. In addition, there is considerable variance among studies in the choice of life events, and concrete information on the variables used to measure the gerontographic life stages is lacking ${ }^{(53)}$, because the model is proprietary ${ }^{(17)}$.

\section{Time perspective}

Socio-emotional selectivity theory is another approach that looks at the effect of life events on behaviour ${ }^{(54)}$. Rather than focusing on self-perception (like cognitive age) or adaptation (life course perspectives), it assumes that differences in behaviour are based on differences in time perspective ${ }^{(55)}$. The theory classifies time perspective into limited time and open-ended time, which can be measured using a reliable, ten-item questionnaire (internal consistency: 0.92) ${ }^{(56)}$. People who perceive time as limited (regularly found in ill or old people) have a tendency to pursue short-term, emotional and present-oriented goals whereas people who perceive time as open-ended (more often found in young people) have a tendency to pursue more long-term, rational and future-oriented goals ${ }^{(55,57)}$.

On a consumer level, hedonic products (for example, tasty food) are most appealing when time is limited, whereas utilitarian products (for example, healthy food) are most appealing when time is open-ended ${ }^{(58)}$. Functional foods usually provide benefits in the long run and may therefore, on the one hand, appeal most to consumers with an open-ended time perspective. On the other hand, the convenience or 'quick fix' aspect of functional foods ${ }^{(59)}$ may appeal to those who perceive time as limited. In line with the latter, elderly living in nursing homes (i.e. who probably perceive time as limited) are more interested in functional foods than those still living independently ${ }^{(60)}$. However, to our knowledge, no published studies have looked at the effect of time perspective on functional food acceptance.

Although time perspective is correlated with age, such that older adults more often perceive time as limited, it is not bound to age ${ }^{(55,58)}$. In fact, larger differences in time perspective exist among elderly than among young adults $^{(61)}$ and the correlation between age and time perspective is not always significant within the elderly population $^{(62,63)}$. In fact, time perspective can even be changed temporarily using time constraints or statements ${ }^{(58,64)}$. Segments based on time perspective are therefore more or less stable depending on the context of food choice. In line with this, test-retest reliability of the future time perspective scale is moderate $(0.50 \text { to } 0.72)^{(65)}$. In addition, as elderly more often perceive time as limited, a segment of elderly who perceive time as open-ended may not be substantial enough to be profitable. In addition, time perspective is not strongly related to demographics other than chronological age ${ }^{(54)}$, and this association is weak within the elderly population ${ }^{(62,63)}$ As a result, information on accessibility of segments based on time perspective will be limited.

Time perspective is, however, strongly related to one's motivations and goals ${ }^{(55)}$ and may therefore provide responsive segments. Emotionally appealing advertisements are, for example, more attractive to consumers who perceive time as limited than to consumers who perceive time as open-ended $^{(66)}$. In addition, time perspective is inferred from responses on a validated, multi-item questionnaire and is therefore moderately easy identifiable. Moreover, segments based on time perspective are actionable for both communication and design, because they provide information about the products and messages that are appealing to consumers (for example, hedonic $v$. utilitarian). A recent conceptualisation of time perspective may provide even more actionability. Cate \& John ${ }^{(54)}$ found that time perspective could best be operationalised as two independent dimensions: perceived limitations and opportunities. In this conceptualisation, a person who sees time as limited does not necessarily see time as less full of opportunity and may be interested in, for example, products that promote health and are convenient to use at the same time.

\section{Demographics}

In contrast with time perspective, demographics are widely used as segmentation bases. They provide segments that are considerably stable (for example, sex), substantial (for example, education), easily identified using objective measures (for example, age ${ }^{(27)}$ and intuitively easy to understand $^{(67)}$. In addition, demographics are often readily available ${ }^{(22)}$ and have been used as a basis for media profiles that provide marketers with information on the accessibility of consumers.

Functional food acceptance has been related to various demographics, such as sex, education, income and age $^{(68,69)}$. Specifically, women and older adults are overall found to be more accepting of functional foods than men and younger adults ${ }^{(18,70)}$, and consumers with lower education have more concerns about functional foods than those with higher education ${ }^{(71)}$, which may also be explained by their lower income. These findings suggest that highly educated, wealthy, elderly women may be most interested in functional foods. 
Nevertheless, differences in demographics generally do not account for much variation in actual food choice $^{(72,73)}$. For example, the core foods eaten by elderly vary little with income ${ }^{(74,75)}$ and the perceived health benefits of functional foods outweigh the effects of age and sex on functional food acceptance ${ }^{(69)}$. Furthermore, segments based on demographics are limited in actionability regarding both product design and communication ${ }^{(35)}$ as they provide little instructions for marketing efforts. For example, how can marketers position functional food in a segment of well-educated, elderly women? In addition, segments are probably not uniquely responsive to marketing efforts because consumers within these segments are often considerably heterogeneous ${ }^{(26)}$. Indeed, relationships found between demographics and food choice differ between functional foods ${ }^{(76)}$, across countries ${ }^{(77)}$, over time ${ }^{(78)}$ and across studies in general.

\section{Summary}

Person-level segmentation bases are generally stable, responsive and substantial. They are, however, limited in their actionability because they are not strongly related to actual food choice. Therefore, these bases provide limited instructions for marketing efforts in the functional food market. Furthermore, demographics and single life events are unique in the sense that they are measured directly with objective, one-item measures (for example, birth date, sex). All other segmentation bases that we discuss are inferred from multi-item questionnaires.

\section{Food-level bases}

Food-level segmentation bases are medial-level bases that indicate, for example, how people think about food and food contexts (for example, 'processed food is unhealthy'), but also how they trade off various reasons for choosing food (for example, health $v$. sensory appeal). Researchers who advocate the use of domain-level bases for market segmentation generally argue that these bases are neither too general (like person-level bases), nor too specific (like product-level bases) $^{(27,79)}$. The same argument may also underline why domain-level bases are of limited use; for some purposes they are neither specific nor general enough. We will evaluate two food-level bases: general food beliefs and food choice motives.

\section{General food beliefs}

The experiences with food that consumers have over their lifetime affect their personal beliefs about food, such as what types of food they should or should not eat, the role of food in their lives and how they categorise or evaluate food products ${ }^{(72,73,80,81)}$. These beliefs are general, in that they are not about specific food products (for example, oranges) but about broader food categories (for example, fruit) or about food in general (for example, the effects of food on health). General food beliefs differ strongly among consumers and, as a consequence, the same type of food (for example, functional food) may be perceived as healthy and convenient by some, but as unhealthy and quick-fix solutions by others ${ }^{(81)}$.

Elderly tend to believe that their diet is already healthy ${ }^{(82,83)}$ and that improving their diet is too late ${ }^{(44,80)}$. Single beliefs are probably not actionable, however, because they do not directly translate into specific behaviours. For example, consumers may overall be sceptical about functional foods, but nevertheless consume specific functional foods that meet their needs or wants ${ }^{(60)}$. A combination of multiple beliefs thus provides a broader perspective of consumer thought processes and food choice. In one of the few segmentation studies of the elderly food market, Morgan ${ }^{(23)}$ segmented elderly using a questionnaire with food-related statements (for example, 'eating at restaurants is too expensive') and found three responsive segments: nutrition concerned, fast and healthy, and traditional couponers. Segments like these are actionable for both product design and communication, because they provide concrete information about the thought processes of consumers. For nutritionconcerned elderly, for example, marketers can emphasise the health aspects of foods and for fast and healthy elderly the convenience aspects.

One well-known questionnaire based on food beliefs is the Food-Related Lifestyle Instrument. It measures sixtynine food beliefs from the process of food shopping to food consumption and links them to five food lifestyle elements ${ }^{(84)}$. However, most researchers construct their own questionnaire, with beliefs that are of central interest for specific research questions. Similar to measuring life events, there is no consensus on which food beliefs should be measured. Nonetheless, the choice of beliefs is a critical step ${ }^{(25)}$ that strongly affects actionability. A segmentation based on beliefs about food in general will provide less information on how a functional food should be designed (actionability for design) but more information on how to approach consumers (actionability for communication) than a segmentation based on beliefs about the more specific category of functional foods.

Substantiality of segments is probably not a problem when using food beliefs, because marketers are not bound to a specific number or type of segments and can thus combine segments that are too small. Furthermore, general food beliefs are based on a lifetime of experiences and can remain consistent over long periods of time ${ }^{(85)}$. In contrast, the more specific beliefs about functional foods may not yet be strongly established in consumers' minds. In earlier studies on functional foods, beliefs used to fluctuate between as well as within experiments ${ }^{(86,87)}$ and although functional foods are more common nowadays, consumers are still ambivalent about them ${ }^{(60,88)}$. Segments based on food beliefs may thus be more or less stable 
depending on the beliefs that are measured. The availability of media profiles and, therefore, accessibility of the segments also depends on the choice of beliefs.

\section{Food choice motives}

Whereas food beliefs consist of what consumers think is true, food choice motives consist of what consumers think is important and which factors they consider in making food choices.

The widely used Food Choice Questionnaire ${ }^{(89)}$ assesses the importance of each of nine food choice motives: health, mood, convenience, sensory appeal, natural content, price, weight control, familiarity and ethical concern (internal consistency of the scales $>0.72$ ). A later adjustment of this scale divides the ethical motive into three motives: religion, political value and ecological welfare ${ }^{(90)}$. Segments based on food choice motives are actionable for both product design and communication, because the motives can be directly translated into product characteristics and messages ${ }^{(91)}$. Segments that are motivated by weight control, for example, may be interested in proteinenriched products that 'increase feelings of satiety' whereas segments that are motivated by natural content may prefer products that 'contain natural sources of protein'.

Usually consumers hold multiple motives ${ }^{(91)}$ that may be more or less important depending on the context of food choice $^{(92)}$. When hospitalised, for example, people often temporarily care less about the sensory appeal of food and focus more on their health ${ }^{(80)}$. In the case of conflicting motives, a trade off takes place, wherein one can, for example, focus on a single motive (for example, always choose the healthiest option). Alternatively, one can routinise ways to trade off motives for recurring situations (for example, only choose tasty foods during the weekend) ${ }^{(81)}$. In addition, consumers may choose to interpret food choice motives in such a way that they are consistent with their behaviour. When consuming ice cream, for example, consumers may operationalise their health motives in terms of promoting wellbeing (i.e. enjoyment) even though the product may not benefit their physical health ${ }^{(93,94)}$. Furthermore, what consumers think is important does not always align with what they actually do ${ }^{(95)}$. Food choice motives are thus probably not strongly predictive of actual food choice.

Trade-off tendencies of food choice motives are relatively stable within situations ${ }^{(81)}$ and, usually, food choice questionnaires measure the importance of food choice motives in the context of 'a typical day'. Food choice motives will, therefore, probably result in stable segments. In line with this, test-retest reliability of the motives ranges between 0.71 and $0.83^{(89)}$. In addition, trade-off tendencies may result in uniquely responsive segments. Although most consumers want products that satisfy as many motives as possible ${ }^{(26)}$, consumers do differ in the relative importance of these motives ${ }^{(92)}$. Among elderly,
Locher et al. ${ }^{(73)}$ found a general interest in the motives convenience, sensory appeal and price, but considerable heterogeneity regarding the motives health, natural content, familiarity and weight control ${ }^{(73,82)}$.

Consumers who are motivated by health are not necessarily willing to try functional foods. These foods are expected to taste badly and perceived to be unnatural, unfamiliar and expensive ${ }^{(18,57,78,87)}$, thus the importance of sensory appeal, natural content, familiarity and price also play a role. In addition, consumers' reasons behind food choice vary across different types of functional food $^{(76,96)}$. As a result, segments based on food choice motives have been found to differ in acceptance of some but not all functional foods ${ }^{(76)}$. This variability limits the responsiveness of segments based on food choice motives.

Furthermore, food choice motives are inferred from responses on the Food Choice Questionnaire, rather than measured directly. The questionnaire is lengthy with its thirty-six items; thus segments based on food choice motives are moderately identifiable. However, there is no consensus regarding the number and type of segments that may be derived from the Food Choice Questionnaire, which increases the influence that marketers have on the substantiality of segments. Segments that are too large may be broken down and segments that are too small may be combined with other segments. Nonetheless, segment substantiality is probably not a problem because segments based on food choice motives are often substantial enough $(\geq 21 \%)^{(67,76)}$. In contrast, segments may not be linked to media profiles, because not all food choice motives are reliably related to specific demographics. The price motive, for example, has been related to age in some studies ${ }^{(67,97)}$ but not in others ${ }^{(89)}$.

\section{Summary}

Food-level segmentation bases are generally responsive and actionable because they are closely related to actual food choice. They are moderately identifiable (because they are inferred from multi-item questionnaires) and provide little information on accessibility (because they are not related to demographics). In addition, their ability to predict acceptance of specific functional foods is limited because they operate on a general food level. For example, consumers who appreciate functional foods in general may not be interested in specific functional food formats.

\section{Product-level bases}

Product-level segmentation bases are low-level bases that indicate, for example, what kind of benefits people seek in their food consumption (for example, 'comfort') and what kind of product attributes they prefer (for example, 'crispy texture'), but also what products consumers actually purchase. Researchers who advocate the use of productlevel bases for market segmentation argue that these are 
strongly predictive of actual food choice ${ }^{(24,98)}$. Others argue that segments based on product-level bases may be too specific and therefore not generalisable to other products $^{(27,36)}$. We will evaluate two product-level bases: product attributes and benefits sought, and past purchase.

\section{Product attributes and benefits sought}

Food choice motives (for example, 'health') are fulfilled by product benefits (for example, 'control of blood pressure') which arise from product attributes (for example, 'added omega-3 fatty acids') ${ }^{(27,99)}$. These three concepts are often used interchangeably ${ }^{(92,100)}$ because they are closely related to each other. However, food choice motives reflect more general consumer tendencies, whereas the attributes and benefits that consumer seek probably differ across foods. Therefore, we evaluate product attributes and benefits together as product-level segmentation bases.

According to Haley ${ }^{(26)}$, the fact that consumers seek different benefits is the main reason why market segments exist. In various marketing domains, elderly consumers have been segmented on the product attributes and benefits they seek ${ }^{(101,102)}$ and this has also been done for the general consumer population in the functional food market $^{(103,104)}$. Examples of resulting segments are: 'receptive to functional foods' ( $47 \%$ ) and 'receptive to general foods for wellbeing' $(53 \%)^{(103)}$, or 'pill lovers' (23\%), 'yoghurt lovers' (16\%) and 'pill loathers' (16\%) ${ }^{(104)}$. Moreover, one of the few researchers who discussed the segmentation of elderly consumers in the food market recommended using benefit segmentation ${ }^{(24)}$. Nonetheless, this recommendation was not evaluated in practice.

The three attributes of functional food that are most frequently discussed in the literature are: functional ingredients (for example, $\mathrm{Ca}$ ), health claims (for example, 'increases bone mineral density') and the carrier product in which functional ingredients are placed (for example, orange juice). These attributes each affect functional food acceptance individually ${ }^{(105)}$. In addition, ingredients and carriers interact with each other ${ }^{(19,106)}$ and, as a result, some carrier-ingredient combinations are more appealing to consumers than others ${ }^{(18,87)}$. Functional food acceptance is also affected by the way in which health claims are presented. For example, elderly prefer health claims that focus on disease prevention (for example, 'reduces risk of cancer') over health claims that focus on health promotion (for example, 'increases energy level') ${ }^{(70)}$. However, carrier type is found to affect acceptance most strongly ${ }^{(19,76,106)}$.

Besides food-specific attributes (for example, functional ingredients), functional foods may differ on a range of general product attributes, such as product price, package, brand and additional ingredients ${ }^{(107-109)}$. These attributes also contribute to the benefits that a product provides. Although individual benefits are appealing to many segments, it is the total configuration of benefits sought that differ between segments ${ }^{(26,92)}$ and result in unique responsiveness. Overall, elderly prefer healthy carriers to unhealthy ones, but considerable differences exist in their specific preferences. For example, elderly are found to overall like protein-enriched bread and dislike proteinenriched candy, but differ in their acceptance of proteinenriched meat, microwave meals and canned soup ${ }^{(60)}$.

Segments based on product attributes and benefits sought are actionable because they can be directly translated into marketing efforts ${ }^{(24,26)}$ (for example, by highlighting certain benefits) as well as product design (for example, by using certain carrier-ingredient combinations). In contrast, identifiability of these segments is limited. Researchers generally advise against directly measuring attributes and benefits sought ${ }^{(105)}$ because consumers often do not exactly know why they do or do not want to purchase certain products $^{(110,111)}$. Instead, researchers usually let participants evaluate product formats, from which the attributes and benefits sought are later derived using a statistical method (for example, conjoint analysis).

Generally, segments based on attributes and benefits sought are substantial enough $(\geq 16 \%)^{(104,112,113)}$ but moderately stable. Sought attributes and benefits are linked to the food choice motives that are most important at the moment of food choice. These motives, in turn, can vary across situations ${ }^{(92)}$ and over time ${ }^{(114)}$. However, when attributes and benefits sought are measured for a specific context, segments may be stable. In line with this, test-retest reliabilities of attributes and benefits sought have been found to vary strongly, from the weak $0 \cdot 20$ to the strong $0 \cdot 93^{(114,115)}$. In addition, products and attributes sought cannot always be directly related to specific demographics ${ }^{(104)}$ and may, therefore, provide little information on the accessibility of segments.

\section{Past purchase}

Aside from which attributes and benefits consumers seek, it can be useful to look at what products consumers actually purchase. Research suggests that past behaviour is strongly predictive of future behaviour $^{(116)}$ and when behaviour is frequently performed, it may turn into a stable habit ${ }^{(117)}$. This applies to food choice as well ${ }^{(118,119)}$. Past purchase may be especially predictive of future purchase in elderly because they live relatively stable lives ${ }^{(120)}$ and may thus have well-established patterns of consumption. Indeed, even olfactory losses in the elderly are not strongly related to changes in food choice ${ }^{(121,122)}$. Segments based on product purchase are thus probably stable.

Nonetheless, the relationship between past and future behaviour is not especially meaningful ${ }^{(116)}$. Past behaviour and future behaviour are merely correlated with each other because they are based on the same underlying beliefs and motivations ${ }^{(123)}$. Behaviour itself does not provide much information on why consumers do or do not purchase certain products and actionability for communication is thus limited. How can one, for example, promote functional 
food purchase among consumers who do not yet purchase functional food? In contrast, actionability for design may be moderate. For example, consumers who already purchase certain types of functional food may be interested in similar types of functional food and consumers may also be approached with functional alternatives of the conventional foods that they purchase.

Information on past behaviour may, however, only be useful in a market that is relatively static and the functional food market, in contrast, is one driven by innovation ${ }^{(124)}$. Product formats or marketing efforts from the past may therefore be a weak starting point in the commercialisation of functional foods. Furthermore, few segmentation studies use purchase behaviour in isolation, because it tends to result in limited, substantial and heterogeneous segments (for example, buyers and non-buyers of a product) that are probably not uniquely responsive to marketing efforts. Therefore, behaviour is sometimes measured in combination with other variables, such as purchase frequency ${ }^{(125)}$ or motivations ${ }^{(107)}$ to establish more diverse segments. Yet more often, past behaviour is used to describe segments rather than as a basis for market segmentation $^{(102,126)}$.

Segments can be identified using a self-report measure of past purchase, but self-report measures often provide unreliable results ${ }^{(127)}$. In addition, consumers may be unaware of functional food purchases because consumers are often unsure whether or not products are 'functional' ${ }^{(60,87)}$. A better source of information is the customer card because it objectively records what customers purchase ${ }^{(128)}$. Moreover, it records purchases across various occasions (for example, week and weekend days), which provides a better indication of behavioural tendencies than a single purchase ${ }^{(129)}$. Furthermore, customer cards are usually linked with customer profiles that contain various demographics as well as store patronage information on which media profiles have been based. This information can thus be used to determine the accessibility of segments. However, irrespective of the measure used, past purchase can only be measured when the product of interest is already for sale in stores. This variable may thus be of limited use for newly developed functional foods.

\section{Summary}

Product-level segmentation bases are unique in the sense that they are able to predict acceptance of specific functional food formats, to some extent. Similar to food-level segmentation bases, segments of product-level bases are relatively strong regarding stability, substantiality and actionability for design. In contrast, segments are not always responsive and actionable for communication. Whereas segments based on product attributes and benefits sought are both actionable and responsive, this is not the case for past purchase. In addition, although past purchase may be the strongest predictor of functional food purchase among the segmentation bases in the present paper, it can exclusively be used for products that are already in stores.

\section{Discussion}

Segmentation of elderly consumers has become increasingly interesting from a marketing perspective ${ }^{(5)}$. Segmentation of elderly in the functional food market has received limited attention, however, which is surprising given its potential for both the marketing industry and health community ${ }^{(13,18)}$. Successful market segmentation calls for a strong theoretical basis and the present review aimed to provide some insight into segmentation bases for elderly in the functional food market. One approach to segmenting elderly consumers is to use characteristics-based segmentation bases that focus on describing consumers (for example, demographics). Another approach would be to use preference-based segmentation bases (for example, food choice motives), which focus on gaining insight into the wants and needs of consumers. In this paper, we argued that elderly have specific food-related needs and wants, and this might justify preference-based segmentation approaches in the functional food market.

The present review evaluated a range of potential segmentation bases on their appropriateness in the context of functional foods for the elderly consumer population. Using seven evaluation criteria based on the marketing literature $\mathrm{e}^{(22,33,34)}$, we found that all segmentation bases had strengths as well as weaknesses (see Table 1). It may thus not be appropriate to use a single segmentation base to segment the elderly consumer population in the functional food market. Although from a descriptive point of view one might combine all segmentation bases and look for useful information within this bulk of data, from an 'understanding' and marketing point of view it may be most useful to use few bases that complement each other in terms of their strengths ${ }^{(22)}$ and provide meaningful segments.

Given that the functional food market calls for segmentation bases that are meaningful in terms of both product design and communication, elderly consumers in this market may best be segmented using a preference-based variable from the food or product level that is predictive of behaviour (for example, attributes and benefits sought), combined with one or more characteristicsbased person-level variables that describe consumer characteristics (for example, demographics). In the end, the effectiveness of (combinations of) segmentation bases remains an empirical matter. We hope that the present review stimulates further empirical research that substantiates the ideas presented in this paper.

\section{Guidelines and conclusion}

This paper underlines that there is no single correct way of segmenting elderly consumers in the functional food 
market. In fact, this is the case for most consumer groups and markets. Nevertheless, a segmentation base will provide the most meaningful segments when it is matched to the marketing objectives of a study. In terms of marketing methods, studies aimed at product development will benefit most from segmentation bases on a concrete, product level, that are strongly related to product acceptance and purchase. In contrast, studies aimed at product positioning and communication call for segmentation bases that provide a broader, more general picture on how to approach consumers. These bases can be found on the more abstract person level. In addition, several practical considerations can guide the selection of segmentation bases. For example, studies that specifically aim to target all consumers in a population may want to use a segmentation base that results in a few, substantial segments (for example, domain- and product-level bases). In contrast, studies that aim to provide international segments or segments that need to be reproducible after a period of time may want to use a segmentation base that provides relatively stable segments across cultures or time, respectively (for example, person-level bases).

\section{Limitations and future research}

The number of bases that can be used to segment consumer populations is virtually limitless ${ }^{(26)}$. The present paper reviewed a selection of eight segmentation bases that are frequently used in either studies on elderly consumers or food choice. However, various other segmentation bases may be useful in segmenting the elderly population within the functional food market and may be an interesting target for future research. In addition, segmentation of the elderly market is relatively understudied in the marketing literature. Therefore, there is little empirical research on diversity in elderly food choices to build on, for now. Similarly, the amount of literature on functional foods was limited and did not include all segmentation bases that were evaluated in the present review. Much of the reasoning in this paper thus remains at a conceptual level. Future empirical research on market segmentation of the elderly consumer population and functional food acceptance will enable these fields to develop and move beyond the conceptual level put forward in this paper.

\section{Acknowledgements}

The present review received no specific grant from any funding agency in the public, commercial or notfor-profit sectors. L. D. T. v. d. Z. is supported by the 'IPOP Customized Nutrition' programme financed by Wageningen University and Research Centre (Wageningen UR), the Dutch Ministry of Economic Affairs, Agriculture and Innovation and the Wageningen School of Social Sciences (WASS) graduate school.
L. D. T. v. d. Z. drafted the manuscript. All authors contributed to and approved the final version of the manuscript.

The authors declare that there are no conflicts of interest.

\section{References}

1. United States Census Bureau (2010) The next four decades, the older population in the United States: 2010 to 2050. Current population reports: Population estimates and projections (series P25, no. 1138). Washington, DC: United States Department of Commerce. http://www.census.gov/ prod/2010pubs/p25-1138.pdf (accessed October 2013).

2. Commission European (2009) The social situation in the European Union 2009. Luxembourg: Publications Office of the European Union. http://aei.pitt.edu/40813/1/social_ 2009.pdf (accessed October 2013).

3. Karani KG \& Fraccastoro KA (2010) Resistance to brand switching: the elderly consumer. J Bus Econ Res 8, 77-84.

4. Mathur A, Sherman E \& Schiffman LG (1998) Opportunities for marketing travel services to new-age elderly. J Serv Mark 12, 265-277.

5. Purinton-Johnson EF (2013) Segmenting the mature market: have marketers matured along with their market? Proceedings of the American Society of Business and Behavioral Science, vol. 20, no. 1, pp. 579-588 [J Zhu and WI Mondal, editors]. Las Vegas: ASBBS. http://asbbs.org/ files/ASBBS2013/PDF/P/Purinton-JohnsonE(P579-588).pdf (accessed October 2013).

6. Moschis GP (2003) Marketing to older adults: an updated overview of present knowledge and practice. J Consum Mark 20, 516-525.

7. Arboleya S, González S, Salazar N, et al. (2012) Development of probiotic products for nutritional requirements of specific human populations. Eng Life Sci 12, 368-376.

8. World Health Organization (2004) Vitamin and Mineral Requirements in Human Nutrition, 2nd ed. Geneva: World Health Organization.

9. Brownie A (2006) Why are elderly individuals at risk of nutritional deficiency? Int J Nurs Pract 12, 110-118.

10. Marinangeli CPF \& Jones PJH (2013) Gazing into the crystal ball: future considerations for ensuring sustained growth of the functional food and nutraceutical marketplace. Nutr Res Rev 26, 12-21.

11. Roininen K, Lähteenmäki L \& Tuorila H (1999) Quantification of consumer attitudes to health and hedonic characteristics of foods. Appetite 33, 71-88.

12. Leek S, Szmigin I \& Carrigan M (2001) Older consumers and food innovation. J Int Food Agribus Mark 12, 71-89.

13. Yoon C \& Cole CA (2009) Aging and consumer behavior. In Handbook of Consumer Psychology, pp. 247-270 [CH Haugtvedt, PM Herr and FR Kardes, editors]. New York: Psychology Press.

14. Dunne JL \& Dahl WJ (2007) A novel solution is needed to correct low nutrient intakes in elderly long-term care residents. Nutr Rev 65, 135-138.

15. Crowe KM \& Francis C (2013) Position of the Academy of Nutrition and Dietetics: functional foods. J Acad Nutr Diet 113, 1096-1103.

16. Tepper K (1994) The role of labeling responses processes to age in elderly consumers' segmentation cues. J Consum Res 20, 503-519.

17. Faranda WT \& Schmidt SL (1999) Segmentation and the senior traveler: implications for today's and tomorrow's aging consumer. J Travel Tourism Mark 8, 3-27. 
18. Poulsen JB (1999) Danish consumers' attitudes towards functional foods (MAPP Working Paper 62). Aarhus, Denmark: The Aarhus School of Business. https://pure. au.dk/portal/files/32326738/0003008.pdf (accessed October 2013).

19. Siegrist M, Stampfli N \& Kastenholz H (2008) Consumers' willingness to buy functional foods. The influence of carrier, benefit and trust. Appetite 51, 526-529.

20. Vassallo M, Saba A, Arvola A, et al. (2009) Willingness to use functional breads. Applying the health belief model across four European countries. Appetite 52, 452-460.

21. Moschis GP (1992) Gerontographics: a scientific approach to analyzing and targeting the mature market. J Serv Mark 6, $17-26$.

22. Wedel M \& Kamakura WA (2000) Market Segmentation: Conceptual and Methodological Foundations. Norwell, MA: Kluwer Academic Publishers.

23. Morgan CM. Segmentation study aims to help marketers understand diverse seniors market. Quirk's Marketing Research Review. http://www.quirks.com/articles/a1993/ 19931002.aspx (accessed October 2013).

24. Ahmad R (2003) Benefit segmentation: a potentially useful technique of segmenting and targeting older consumers. Int J Mark Res 45, 373-389.

25. Hair JF Jr, Black WC, Babin BJ, et al (2010) Cluster analysis. In Multivariate Data Analysis, chapter 9, 7th ed., pp. 505-564 [JF Hair Jr, WC Black, BJ Babin and RE Anderson, editors]. Upper Saddle River, NJ: Pearson Prentice Hall.

26. Haley RI (1968) Benefit segmentation: a decision-oriented research tool. J Mark 32, 30-35.

27. Van Raaij WF \& Verhallen TMM (1991) Domain-specific market segmentation. Eur J Mark 28, 49-66.

28. Goldsmith RE, Freiden JB \& Eastman JK (1995) The generality/specificity issue in consumer innovativeness research. Technovation 15, 601-612.

29. Ansari A, Essegaier S \& Kohli R (1999) Internet recommendation systems. J Mark Res 37, 363-375.

30. Greengrove K (2002) Needs-based segmentation: principles and practice. Int J Mark Res 44, 405-421.

31. Greenberg G \& McDonald SS (1989) Successful needs/benefits segmentation: a user's guide. J Consum Mark 6, 29-36.

32. Finley DS, Rogers G, Napier M, et al. (2011) From needsbased segmentation to program realignment: transformation of YWCA of Calgary. Admin Soc Work 3, 299-323.

33. Dibb S (1999) Criteria guiding segmentation implementation: reviewing the evidence. J Strateg Mark 7, 37-41.

34. Kotler P (1984) Market Management. Englewood Cliffs, New York: Prentice-Hall.

35. Steenkamp JEM \& Ter Hofstede F (2002) International market segmentation: issues and perspectives. Int $J$ Res Mark 19, 185-213.

36. Sudbury L \& Simcock P (2009) Understanding older consumers through cognitive age and the list of values: a UK-based perspective. Psychol Mark 26, 22-38.

37. Lumbers M \& Raats M (2006) Food choices in later life. In The Psychology of Food Choice, pp. 289-310 [R Shepherd and M Raats, editors]. Wallingford: CABI Publishing.

38. Bone PF (2007) Identifying mature segments. I Consum Mark 8, 19-32.

39. Settersten RA Jr \& Mayer KU (1997) The measurement of age, age structuring, and the life course. Annu Rev Sociol 23, 233-261.

40. Mathur A \& Moschis GP (2005) Antecedents of cognitive age: a replication and extension. Psychol Mark 22, 969-994.

41. Barak B \& Schiffman LG (1981) Cognitive age: a nonchronological age variable. Adv Consum Res 8, 602-606.
42. Barak B \& Rahtz DR (1999) Perceived youth: appraisal and characterization. Int J Aging Hum Dev 49, 231-257.

43. Van Auken S \& Barry TE (2009) Assessing the nomological validity of a cognitive age segmentation of Japanese seniors. Asia Pac J Mark Logist 21, 315-328.

44. Delaney M \& McCarthy M (2009) Food choice and health across the life course: a qualitative study examining food choice in older Irish adults. J Food Prod Mark 17, 114-140.

45. Barak B \& Gould S (1985) Alternative age measures: a research agenda. Adv Consum Res 12, 53-58.

46. Kotilainen L, Rajalahti R, Ragasa C, et al (2006) Health Enhancing Foods: Opportunities for Strengthening the Sector in Developing Countries: Agricultural and Rural Development Discussion Paper 30. Washington, DC: The World Bank.

47. Moschis GP \& Mathur A (2006) Older consumer responses to marketing stimuli: the power of subjective age. J Advert Res 46, 339-346.

48. Sobal J \& Bisogni CA (2009) Constructing food choice decisions. Ann Behav Med 38, Suppl. 1, S37-S46.

49. Mathur A, Moschis GP \& Lee E (2008) A longitudinal study of the effects of life status changes on changes in consumer preferences. J Acad Mark Sci 36, 234-246.

50. Moschis G, Curasi C \& Bellenger D (2007) Patronage motives of mature consumers in the selection of food and alcoholic beverage brands. J Food Prod 13, 61-80.

51. Moschis G, Curasi C \& Bellenger D (2004) Patronage motives of mature consumers in the selection of food and grocery stores. J Consum Mark 21, 123-133.

52. Moschis GP, Lee E, Mathur A, et al (2000) The Maturing Marketplace: Buying Habits of Baby Boomers and Their Parents. Westport, CT: Quorum Books.

53. Weijters B \& Geuens M (2003) Segmenting the senior market: professional and social activity level. Asia Pacific Adv Consum Res 5, 140-147.

54. Cate RA \& John OP (2007) Testing models of the structure and development of future time perspective: maintaining a focus on opportunities in middle age. Psychol Aging 22, $186-201$.

55. Carstensen LL, Fung HH \& Charles ST (2003) Socioemotional selectivity theory and the regulation of emotion in the second half of life. Motiv Emot 27, 103-123.

56. Lang FR \& Carstensen LL (2002) Time counts: future time perspective, goals, and social relationships. Psychol Aging 17, 125-139.

57. Ares G, Giménez A \& Gámbaro A (2008) Uruguayan consumers' perception of functional foods. J Sens Stud $\mathbf{2 3}$ 614-630.

58. Wei Y, Donthu N \& Bernhardt KL (2012) Effects of cognitive age, dispositional time perceptions, and time view manipulations on product attribute evaluations. J Bus Res 66, 2171-2177.

59. Cornish LS (2012) It's good for me: it has added fibre! An exploration of the role of different categories of functional foods in consumer diets. J Consum Behav 11, 292-302.

60. Van Der Zanden LDT, Van Kleef E, De Wijk RA, et al. (2014) Knowledge, perceptions and preferences of elderly regarding protein-enriched functional food. Appetite 80, 16-22.

61. Fung HH, Lai P \& Ng R (2001) Age differences in social preferences among Taiwanese and mainland Chinese: the role of perceived time. Psychol Aging 16, 351-356.

62. Bal PM, Jansen PGW, Van Der Velde MEG, et al. (2010) The role of future time perspective in psychological contracts: a study among older workers. J Vocat Behav 76, 474-486.

63. Fredrickson BL \& Carstensen LL (1990) Choosing social partners: how old age and anticipated endings make people more selective. Psychol Aging 5, 335-347. 
64. Kim S, Goldstein D, Hasher L, et al. (2005) Framing effects in younger and older adults. J Gerontol Psychol Sci Soc Sci 60, $215-218$.

65. Zacher H \& De Lange AH (2011) Relations between chronic regulatory focus and future time perspective: results of a cross-lagged structural equation model. Pers Individ Differ 50, $1255-1260$

66. Williams P \& Drolet A (2005) Age-related differences in responses to emotional advertisements. J Consum Res 32, 343-354.

67. Honkanen P, Olsen SO \& Myrland $\varnothing$ (2004) Preferencebased segmentation: a study of meal preferences among Norwegian teenagers. J Consum Behav 3, 235-250.

68. Childs NM \& Poryzees GH (1997) Foods that help prevent disease: consumer attitudes and public policy implications. J Consum Mark 14, 433-447.

69. Verbeke W (2006) Consumer acceptance of functional foods: socio-demographic, cognitive and attitudinal determinants. Food Qual Prefer 16, 45-57.

70. Bogue J \& Ryan M (2000) Market-Oriented New Product Development: Functional Foods and The Irish Consumer. Agribusiness Discussion Paper 27. Cork: Department of Food Economics, National University of Ireland.

71. Niva M \& Mäkelä J (2007) Finns and functional foods: sociodemographics, health efforts, notions of technology and the acceptability of health-promoting foods. Int J Consum Stud 31, 34-45.

72. Rozin P (2006) The integration of biological, social, cultural and psychological influences on food choice. In The Psychology of Food Choice, pp. 19-39 [R Shepherd and M Raats, editors]. Wallingford: CABI Publishing.

73. Locher JL, Ritchie CS, Roth DL, et al. (2009) Food choice among homebound older adults: motivations and perceived barriers. J Nutr Health Aging 13, 659-664.

74. Fanelli MT \& Stevenhagen KJ (1985) Characterizing consumption patterns by food frequency methods: core foods and variety of foods in diets of older Americans. $\mathrm{J} \mathrm{Am}$ Diet Assoc 85, 1570-1576.

75. Briley ME (1998) The determinants of food choices of the elderly. J Nutr Elder 9, 39-45.

76. Ares G \& Gámbaro A (2008) Influence of gender, age and motives underlying food choice on perceived healthiness and willingness to try functional foods. Appetite 49, 148-158.

77. Payette H \& Shatenstein B (2005) Determinants of healthy eating in community-dwelling elderly people. Can J Public Health 96, 27-31.

78. Verbeke W (2006) Functional foods: consumer willingness to compromise on taste for health? Food Qual Pref $\mathbf{1 7}$, 126-131.

79. Geeroms N, Verbeke W \& Kenhove PV (2008) Health advertising to promote fruit and vegetable intake: application of health-related motive segmentation. Food Qual Pref 19, 481-497.

80. Herne S (1995) Research on food choice and nutritional status in elderly people: a review. Br Food J 97, 12-29.

81. Sobal JA, Bisogni CA, Devine CM, et al (2006) A conceptual model of the food choice process over the life course. In The Psychology of Food Choice, pp. 1-18 [R Shepherd and $\mathrm{M}$ Raats, editors]. Wallingford: CABI Publishing.

82. De Almeida MD, Graça P, Afonso C, et al. (2001) Healthy eating in European elderly: concepts, barriers and benefits. J Nutr Health Aging 5, 217-219.

83. Kremer S, Hulst J \& Boesveldt S (2013) Eating behaviour of healthy, independent living Dutch seniors. An exploratory study. Appetite 71, 480.

84. Grunert KG, Brunsø K \& Bisp S (1993) Food-Related Life Style: Development of a Cross-Culturally Valid Instrument for Market Surveillance: MAPP Working Paper 12. Aarhus, Denmark: The Aarhus School of Business.

85. Edstrom KM \& Devine CM (2001) Consistency in women's orientations to food and nutrition in midlife and older age: a 10-year qualitative follow-up. J Nutr Educ 33, $215-223$.

86. Urala N \& Lähteenmäki L (2007) Consumers' changing attitudes towards functional foods. Food Qual Pref 18, 1-12.

87. Landström E, Hursti UK \& Magnusson M (2009) Functional foods compensate for an unhealthy lifestyle: some Swedish consumers' impressions and perceived need of functional foods. Appetite 53, 34-43.

88. Coleman KL, Miah EM, Morris GA, et al. (2013) Impact of health claims in prebiotic-enriched breads on purchase intent, emotional response and product liking. Int J Food Sci Nutr 65, 164-171.

89. Steptoe A, Pollard TM \& Wardle J (1995) Development of a measure of the motives underlying the selection of food: the Food Choice Questionnaire. Appetite 25, 267-284.

90. Lindeman M \& Väänänen M (2000) Measurement of ethical food choice motives. Appetite 34, 55-59.

91. Kornelis M, Van Herpen E, Van Der Lans I, et al. (2010) Using non-food information to identify food-choice segment membership. Food Qual Pref 21, 512-520.

92. Onwezen MC, Reinders MJ, Van Der Lans IA, et al. (2012) A cross-national consumer segmentation based on food benefits: the link with consumption situations and food perceptions. Food Qual Pref 24, 276-286.

93. Chrysochou P, Askegaard S, Grunert KG, et al. (2010) Social discourses of healthy eating. A market segmentation approach. Appetite 55, 288-297.

94. Van Dam YK \& Van Trijp HCM (2013) Relevant or determinant: importance in certified sustainable food consumption. Food Qual Pref 30, 93-101.

95. Urala N (2004) Lähteenmäki L Attitudes behind consumers' willingness to use functional foods. Food Qual Pref $\mathbf{1 5}$ 793-803.

96. Aschemann-Witzel J, Maroscheck N \& Hamm U (2013) Are organic consumers preferring or avoiding foods with nutrition and health claims? Food Qual Pref 30, 68-76.

97. Pohjanheimo T \& Sandell M (2009) Explaining the liking for drinking yoghurt: the role of sensory quality, food choice motives, health concern and product information. Int Dairy J 19, 459-466.

98. Huffman C, Ratneshwar S \& Mik DG (1997) Consumer goal structures and goal-determination processes. In The Why of Consumption, pp. 9-35 [S Ratneshwar, DG Mick and C Huffman, editors]. London: Routledge.

99. Surai PF \& Sparks NHC (2001) Designer eggs: from improvement of egg composition to functional food. Trends Food Sci Technol 12, 7-16.

100. Olsen SO, Prebensen N \& Larsen TA (2009) Including ambivalence as a basis for benefit segmentation: a study of convenience food in Norway. Eur J Mark 43, $762-783$.

101. Horneman L, Carter RW, Wei S, et al. (2002) Profiling the senior traveler: an Australian perspective. J Travel Res 41, 23-37.

102. Shoemaker S (2010) Segmenting the mature market: 10 years later. $J$ Travel Res 39, 11-26.

103. Herath D, Cranfield J \& Henson S (2008) Who consumes functional foods and nutraceuticals in Canada? Results of cluster analysis of the 2006 survey of Canadians' demand for food products supporting health and wellness. Appetite 51, 256-265.

104. Hailu G, Boecker A, Henson S, et al. (2009) Consumer valuation of functional foods and nutraceuticals in 
Canada. A conjoint study using probiotics. Appetite 52, $257-265$.

105. Van Kleef E, Van Trijp HCM \& Luning P (2005) Functional foods: health claim-food product compatibility and the impact of health claim framing on consumer evaluation. Appetite 44, 299-308.

106. Krutulyte R, Grunert KG, Scholderer J, et al. (2011) Perceived fit of different combinations of carriers and functional ingredients and its effect on purchase intention. Food Qual Pref 22, 11-16.

107. Sparke K \& Menrad K (2006) Cross-European and functional food-related consumer segmentation for new product development. J Food Prod Mark 15, 213-230.

108. Bogue J, Sorenson D \& Keeffe MO (2009) Cross-category innovativeness as a source of new product ideas: consumers' perceptions of over-the-counter pharmacological beverages. Food Qual Pref 20, 363-371.

109. Ares G, Besio M, Giménez A, et al. (2010) Relationship between involvement and functional milk desserts intention to purchase. Influence on attitude towards packaging characteristics. Appetite 55, 298-304.

110. Ulwick AW (2002) Turn customer input into innovation. Harv Bus Rev 80, 91-97.

111. Riquelme H (2001) Do consumers know what they want? J Consum Mark 18, 437-448.

112. Chung HS, Hong H, Kim K, et al. (2011) Consumer attitudes and expectations of ginseng food products assessed by focus groups and conjoint analysis. J Sens Stud 26, $346-357$

113. Hsu CHC \& Lee EJ (2002) Segmentation of senior motorcoach travelers. J Travel Res 40, 364-373.

114. Calantone RJ \& Sawyer AG (1978) The stability of benefit segments. J Mark Res 15, 395-404.

115. Bottomley PA \& Doyle JR (2001) A comparison of three weight elicitation methods: good, better, and best. Omega 29, 553-560.

116. Ouellette JA \& Wood W (1998) Habit and intention in everyday life: the multiple processes by which past behavior predicts future behavior. Psychol Bull 124, $54-74$.

117. Conner M \& Armitage CJ (2006) Social psychological models of food choice. In The Psychology of Food Choice, pp. 41-57 [R Shepherd and M Raats, editors]. Oxfordshire, UK: CABI Publishing.

118. Gillespie AMH \& Johnson-Askew WL (2009) Changing family food and eating practices: the family food decisionmaking system. Ann Behav Med 38, 31-36.

119. Peters E (2009) A perspective on eating behaviors from the field of judgment and decision making. Ann Behav Med 38, 81-87.

120. Amireault S, Godin G, Vohl M, et al. (2008) Moderators of the intention-behaviour and perceived behavioural control-behaviour relationships for leisure-time physical activity. Int J Behav Nutr Phys Activ 5, 7.

121. Koster EP (2009) Diversity in the determinants of food choice: a psychological perspective. Food Quality Pref 20, $70-82$.

122. Kremer S, Bult JHF, Mojet J, et al. (2007) Compensation for age-associated chemosensory losses and its effect on the pleasantness of a custard dessert and a tomato drink. Appetite 48, 96-103.

123. Ajzen I (1987) Attitudes, traits, and actions: dispositional prediction of behavior in personality and social psychology. In Advances in Experimental Social Psychology, vol. 20, pp. 1-63 [L Berkowitz, editor]. San Diego, CA: Academic Press.

124. Bäckström A, Pirttilä-Backman AM \& Tuorila H (2003) Dimensions of novelty: a social representation approach to new foods. Appetite 40, 299-307.

125. Barrena R (2009) Sánchez M Consumption frequency and degree of abstraction: a study using the laddering technique on beef consumers. Food Qual Pref 20, 144-155.

126. Littrell MA, Paige RC \& Song K (2004) Senior travellers: tourism activities and shopping behaviours. I Vacation Mark 10, 348-362.

127. Macdiarmid J \& Blundell J (1998) Assessing dietary intake: who, what and why of under-reporting. Nutr Res Rev 11, 231-253.

128. Ziliani C \& Bellini S (2004) Retail micro-marketing strategies and competition. Int Rev Retail Distrib Consum Res 14, $7-18$.

129. Fishbein M \& Ajzen I (1974) Attitudes toward objects as predictors of single and multiple behavioral criteria. Psychol Rev 81, 59-74. 